How to Distinguish Normal from Disordered Children with Poor Language or Motor Skills

Murray J. Dyck ${ }^{1}$ and Jan P. Piek ${ }^{2}$

${ }^{1}$ School of Psychology, Griffith University, Gold Coast, Queensland, Australia, 4222

${ }^{2}$ School of Psychology, Curtin University of Technology, Box U1987, Perth, Western Australia, 6845

Running head: Normal \& Disordered Low Achievement

Correspondence to:

Murray J. Dyck, School of Psychology, Griffith University, Gold Coast, Queensland, Australia, 4222

Tel: 61755528251

Fax: 61755528291

Email: m.dyck@griffith.edu.au 
Abstract

Background \& Aims: We tested the DSM hypothesis that so-called specific developmental disorders are marked by a pattern of specific discrepant achievement, and an alternative hypothesis that children with these disorders show a pattern of relatively pervasive low achievement. Method: Children with a diagnosis of Mixed Receptive Expressive Language Disorder (RELD; n=21) were compared with children with no previously suspected disorder but low standard language scores $(<80 ; n=22)$ selected from a representative sample, and children with Developmental Coordination Disorder (DCD; n=20) were compared with children with no previously suspected disorder but low standard motor skills scores $(n=28)$ selected from a representative sample. Results: Children with diagnosed disorders were more pervasive underachievers. The RELD group obtained lower scores on measures of verbal comprehension, emotion understanding, theory of mind, working memory and response inhibition; the DCD group obtained lower scores on measures of perceptual organization, verbal comprehension, receptive and expressive language, and visual inspection time. Conclusion: We conclude that relatively pervasive underachievement distinguishes disordered from normal low achievers.

Keywords: Discrepancy criterion, cognitive development, developmental disorder, Developmental Coordination Disorder, Mixed Receptive-Expressive Language Disorder, language impairment, motor skills 
According to DSM-IV (American Psychiatric Association, 2000), achievement in language, motor skills, or academic skills that is substantially lower than a child's general intelligence (the discrepancy criterion) and which interferes with the child's academic or occupational achievement, daily living, or social communication indicates that the child has a developmental disorder, specifically, a communication, coordination, or learning disorder. Anything that interferes with a child's achievement, living and social communication skills is, by definition, a problem for the child, but at issue is whether the problem should be identified as a developmental disorder given that this is defined as development which has been affected by physical impairment, structural anomaly, or disease. Current definitions of so-called specific developmental disorders imply that children who underachieve in language, motor, or academic skills have mutually discriminable disorders that result from different neurocognitive impairments, which researchers then seek to identify. But what if discrepant achievement is not a sign of disorder?

There are several reasons for doubting that discrepant achievement is a sign of disorder. The first reason is that children rarely satisfy diagnostic criteria for only a single disorder. Notwithstanding how specific developmental disorders are defined, if we examine the characteristics of children who are identified as having one of these disorders, what we observe is that their characteristics do not match those that are used to define the disorder. Based on the DSM-IV definition of Developmental Coordination Disorder (DCD), we might expect a child with a diagnosis of DCD to have very poor motor skills (which might interfere with such academic tasks as printing or writing) but to achieve normally on non-motor tasks. This expected pattern 
is rarely observed in research on DCD or other developmental disorders (Zoia, Barnett, Wilson \& Hill, 2006). Rather, children who meet criteria for DCD typically also meet criteria for a Communication (Wisdom et al., 2007), Attention-Deficit (Kaplan, Wilson, Dewey \& Crawford, 1998; Pitcher, Piek \& Hay, 2003) or Learning Disorder (e.g., Reading Disorder; Brookes, Nicolson \& Fawcett, 2007; Ramus, Pidgeon \& Frith, 2003), and if permitted by DSM-IV differential diagnosis rules, would also often meet criteria for a Pervasive Developmental Disorder (Green et al., 2002; Wisdom et al.). To identify a child with any specific developmental disorder is usually to identify a child who is a relatively pervasive underachiever.

A second reason for doubting that achievement discrepancies are a sign of disorder is that it has been shown that underachievement, not discrepant achievement, is associated with parent-rated social and behavioral problems in a representative sample of children (Dyck, Hay et al., 2004; cf. Francis et al., 1996; Vellutino et al., 2004). Similarly, it is low achievement within a domain, not whether a child also has a low or high IQ, that best defines whether a child has a learning (Gonzalez \& Espinel, 1999; Stanovich \& Stanovich, 1997; Sternberg \& Grigorenko, 2002; Vellutino, Scanlon, \& Lyon, 2000) or a language problem (Botting, 2005; cf. Karmiloff-Smith, 2007; Karmiloff-Smith, Scerif \& Ansari, 2003). In fact, whether a child has specific ability scores that are much lower than the child's IQ score mainly depends on the child's IQ. The probability of observing a 2 SD discrepancy between IQ and an independent ability test (IQ > other ability) varies from about 0 in children with an IQ of 70 or less to more than .5 in children with an IQ of 130 or more (Dyck, Hay et al.). 
A third reason for doubting that achievement discrepancies are a sign of disorder is that the pattern of scores that is defined as disordered by DSM-IV is identical to the pattern of scores that is to be expected among low achieving typical children. Among typical children, how closely a child's ability in one area (say motor skills) ought to resemble ability in another area (say language or IQ) is described by the correlations between scores on the respective ability tests. Assuming the correlation between motor skills and IQ is 0.21 and between motor skills and language is .22 (Dyck, Hay et al.), and without making any assumptions about how performance in one ability domain may affect performance in any other ability domain, a child who achieves a standard motor skills score of 70 is predicted to achieve an IQ score of 93.7 and a standard language score of 93.4. A language score of 70 is two standard deviations below the mean, and would be recognized as "substantially below" the child's predicted general intellectual ability, which is clearly within the average range and so would satisfy the discrepancy criterion. On average (how closely the values for individual children will approximate the predicted value will depend on the breadth of the confidence intervals), where correlations between abilities are weak, low achieving typical children are expected to show ability profiles in which large discrepancies are common and most scores are not much below the population mean. Where correlations are stronger, smaller discrepancies and lower scores would be expected. If a poor language score of 70 had been used as the basis for prediction in the example, and assuming a correlation between language and IQ of .66 (Dyck, Hay et al.), the child's predicted IQ score would be 80.2 (and motor skills score 93.4). Clearly, what is expected of typical, but low achieving, children cannot be what defines disordered development. Even if it were true that children with some 
disorders were often discrepant achievers, because large discrepancies are also expected among low scoring typical children, the discrepancy criterion would not be useful in discriminating normal from disordered low achievers.

The fact that the discrepancy criterion cannot distinguish between children who are low achievers but do not have a developmental disorder and those who do, means that in the absence of any other agreed way of specifying which low achieving children underachieve as the result of disorder (as opposed to representing the lower tail of a normally distributed ability function), the validity of the discrepancy criterion cannot be directly assessed. For example, we might predict that if the DSM discrepancy criterion is valid, then children with DCD or a language impairment should show more specific deficits (in motor skills / language), that is, deficits only in the area of motor skills or language, than low achieving children without a diagnosis who have been selected from the normal population. However, a failure to observe a difference in ability profiles might be taken to indicate that the children without a diagnosis should have been given one. Or, if children who have received a diagnosis of disorder were found not to be discrepant achievers or were found to underachieve across several ability domains, these results could be taken to indicate that the children had been misdiagnosed in the former case or had comorbid disorders in the latter case. As it stands, although we can assess whether children with a diagnosis of disorder show the discrepant achievement profiles they are expected to show, the DSM hypothesis that specific developmental disorders are characterized by discrepant achievement is not falsifiable.

What can be falsified is an alternative hypothesis. If we can assume that: (a) children with a disorder will differ from low achieving typical children in some 
characteristic way, and (b) if a pattern of discrepant achievement is what is expected of low achieving typical children, then, (c) consistent with the high rates of comorbidity that have been observed in children with any developmental disorder, we can speculate that $(\mathrm{d})$ children with a disorder will be relatively pervasive underachievers, that is, they will tend to attain low scores on a range of ability measures other than those used to define their primary disorder. The aim of this study was to test this hypothesis. We selected two disorders-Mixed Receptive-Expressive Language Disorder (RELD) and DCD—as having particular value to test this hypothesis. In RELD, a child is required to substantially underachieve in both receptive and expressive language compared with the child's achievement on intelligence tests. Large discrepancies in achievement between language / IQ measures are statistically unlikely because of the strong correlation between them. Evidence that children with RELD show a greater discrepancy between language and IQ than typical low scoring children would provide strong counter-intuitive evidence in support of the discrepancy criterion. In DCD, a child is required to underachieve on motor skills tasks compared to the child's achievement on IQ tests. Because motor skills and IQ are weakly correlated in typical children, large discrepancies in achievement are to be expected in all children.

Although the focus of our research was on discrepancies between language or coordination and IQ, children with a language or coordination disorder also have achievement deficits in other domains, including social cognition (Cummins, Piek \& Dyck, 2005; Larson \& McKinley, 1995; Wisdom et al., 2007) and executive functioning (Archibald \& Gathercole, 2006; Dewey, Kaplan, Crawford, \& Wilson, 2002; Piek, Dyck, Francis \& Conwell, 2007; Wisdom et al., 2007). For this reason, 
research into the achievement profiles of children with specific developmental disorders needs to assess a broad range of ability domains. We assessed social cognition, executive functions, and visual inspection time as well as IQ, motor coordination, and language abilities.

Method

\section{Participants and Procedure}

Participants were children aged 3 to 14 years with a DSM-IV (American Psychiatric Association, 2000) diagnosis of RELD, or had identified motor skills problems which satisfied DSM-IV diagnostic criteria for DCD, or were selected from a representative sample of children based on their relatively low language or motor skills. Participants were recruited after the research had been approved by Curtin University Human Research Ethics Committee.

Participants initially recruited to the RELD group were 30 children (male=22) aged between 3 years, 10 months and 12 years, 3 months $(M=6.78$ years, $S D=1.85$ years) from Language Development Centres in Perth, Australia. Consistent with DSM-IV, each child had been diagnosed by a pediatrician, psychologist, or speech pathologist based on the results of standardized testing of receptive language, expressive language, and IQ, and based on parent / teacher reports of significant impairments in social communication and academic functioning. Parents were asked to report any other disorders that had been diagnosed. In 6 cases, one or more additional developmental disorder was reported. Comorbid disorders included attention deficit disorder $=3$, learning disorder $=1$, and motor dyspraxia (Developmental Coordination Disorder in DSM-IV) $=3$. No physical disorders likely to affect performance were reported. Because these children with comorbid disorders 
were therefore known to be relatively pervasive underachievers, they were excluded from the study. A large proportion of data from 3 additional cases was missing and so these cases were also excluded. The final sample consisted of 21 children (male=16) with a mean age of 7.05 years $(\mathrm{SD}=1.76$ years $)$.

Participants initially recruited to the DCD group were 22 children $($ male $=14$ ) aged between 5 years, 0 months and 13 years, 1 month $(\mathrm{M}=8.55$ years, $\mathrm{SD}=2.07$ years) referred by special education teachers and occupational therapists. Because these children had not been formally diagnosed with a motor skills disorder (for reasons unknown, such diagnoses are extremely rare in Western Australia), we confirmed that all referred children had coordination problems by testing them with the Movement Assessment Battery for Children (Henderson \& Sugden, 1992); each child scored at the $5^{\text {th }}$ percentile or lower. In line with DSM-IV criteria, these children's motor coordination problems were judged to have significantly affected their academic achievement or activities of daily living, and it was for this reason that these children were in special education or occupational therapy programs. Parents were asked to report any other disorders that had been diagnosed. In 2 cases, an attention deficit disorder was reported. No physical disorders likely to affect performance were reported. The 2 children with an attention disorder were excluded. The final sample consisted of 20 children (male $=13$ ) with a mean age of 8.43 years $(\mathrm{SD}=2.14$ years $)$.

From a sample of 449 children who represented the distribution of academic achievement within Western Australia (Dyck et al., 2006), we selected children to form two comparison groups based on poor language or motor ability. Language ability was estimated with four subscales from the third edition of the Clinical 
Evaluation of Language Fundamentals (CELF; Semel et al., 1995)—Concepts and Directions, Word Classes, Recalling Sentences, and Formulated Sentences—which were selected because they are the only CELF scales administered to all age groups and because they sample receptive (Concepts and Directions, Word Classes) and expressive (Recalling Sentences, Formulated Sentences) language. Children with standardized language scores $<80$ comprised a relatively poor language ability (PLA) group. 37 children with a mean age of 9.54 years, $S D=2.65$ years, satisfied the criterion. Mean combined receptive and expressive language scores of children in the PLA group did not differ from those of children in the RELD group, but they were significantly older $[t(63.73)=4.98, p<.001$; Levene's test $]$. We then excluded 15 children aged more than 10 years 3 months from the PLA group, leaving it with 22 children $($ male $=14)$ with a mean age of 7.53 years $(\mathrm{SD}=1.59$ years). The final PLA and RELD groups did not differ in age $[t(41)=0.95, n s]$, receptive language ability $[t(29.23)=1.00, n s ;$ Levene's test $]$, or expressive language ability $[t(39)=0.29, n s]$.

From the same representative sample, children with standardized motor coordination and gross motor coordination scores less than 80 comprised a relatively poor motor coordination (PMC) group. Motor coordination was assessed with the McCarron Assessment of Neuromuscular Development (McCarron, 1997). The test comprises 10 tasks, 5 assessing fine motor skills (e.g., putting beads in a box) and 5 assessing gross motor skills (e.g., heel to toe walking). 28 children (male=17) with a mean age of 8.81 years, $S D=3.17$ years, satisfied the criterion. Mean age $[t(46)=0.46$, $n s]$, gross motor coordination $[t(22.15)=0.10, n s ;$ Levene's test $]$ and fine motor coordination $[t(46)=1.10, n s]$ scores of the PMC group did not differ from those of the DCD group. Although 3 participants were in both the PLA and PMC groups, their 
data were retained because their relatively pervasive underachievement makes tests of our hypotheses more conservative.

Participants in the two clinical groups were individually assessed after written informed consent of parents and the oral consent of children was obtained. Testing followed a prescribed order and was conducted in 3 sessions (2.5 hours, 2.5 hours, 1.25 hours) over 2 or 3 days. Participants in the PMC and PLA groups were individually assessed in the same way, or were assessed as part of Project Kids, which involves intensive testing of small groups of children participating for one day in a themed data collection program. Additional details are available in Dyck et al. (2006).

\section{Measures and Data Transformations}

In addition to language and motor skills, we assessed children's intelligence, social cognition, executive functioning, and visual inspection time. The measures used are identical to those reported in Dyck et al., 2006, where extensive information on the reliability and validity of the scales is reported (see summary below). We used data from the representative sample to create standard scores (mean $=100, \mathrm{SD}=15$ ) for each variable to ensure that all scores shared a measurement scale. From these standard scores, we created a set of composite scores, unweighted averages of standard scores on tests that had been defined as part of the ability domain.

Perceptual organization was the average of Block Design and Picture Completion, and verbal comprehension the average of Vocabulary and Information (Wechsler, 1992). Emotion recognition ability was measured with the Fluid Emotions Test (Dyck, Farrugia et al., 2004), which assesses the ability to recognize static and morphed facial expressions of emotion (happiness, sadness, anger, fear, disgust, surprise, contempt; Matusmoto \& Ekman, 1995), and the Vocal Cues Test (Dyck, 
Farrugia et al.) which asesses the ability to recognize vocal intonations specific to different emotions using non-semantic content: numerals, letters, nonsense syllables. Emotion understanding ability was the average of three scales: the Emotion Vocabulary Test (Dyck et al., 2001) measures the ability to define emotion words (what does the word "angry" mean?), the Comprehension Test (Dyck et al.) measures the ability to understand the emotional consequences of exposure to an emotioneliciting context (Susan is given a new bicycle for her birthday. What will Susan feel?), and the Unexpected Outcomes Test (Dyck et al.) measures the ability to apply reasoning skills and knowledge of the causes of emotions to explaining apparent incongruities between an emotion-eliciting context and the emotion elicited by the context. Theory of mind ability was the average of two first-order (the "Sally Ann," Baron-Cohen et al., 1985, and "Smarties," Perner et al., 1989, Wimmer \& Perner, 1983, tasks), one second-order (“Ella the Elephant," Harris et al., 1989), and one advanced ("Strange Stories Test," Happe, 1994) theory of mind tests. Receptive language ability was the average of Concepts and Directions and Word Classes; expressive language ability the average of Formulating Sentences and Recalling Sentences (Semel et al.). Fine motor coordination was the average of fine motor tasks and gross motor coordination the average of the gross motor tasks (McCarron et al., 1997). Response inhibition was the average of two trials of a go go/no go task, a modified version of a task (Shue \& Douglas, 1992) designed to assess simple motor inhibition. Working memory was the average of the two trials of a Trailmaking / Memory Updating Task, a simplification of a more complex task (Rabbit, 1997) designed to assess working memory and behavioral inhibition, and a Goal Neglect Task, which measures the ability to formulate and respond to goal-directed plans 
(Duncan et al., 1996). Visual inspection time was the average of the two trials of a line-length discrimination task (Anderson, 1988). Composite scores were restandardized by calculating age norms (mean and SD in representative sample) for each composite measure so that each score had a mean of 100 and a SD of 15.

\section{Results}

We tested whether achievement profiles are more uniform in children with RELD or DCD by assessing whether they obtained significantly lower scores on the set of ability measures than low scoring comparison groups. To prevent a substantial loss of statistical power as a result of listwise deletion of participants with missing data (up to about $40 \%$ of cases were missing at least one cell), independent t-tests, rather than MANOVA, were used to compare groups, with Levene's formulas used to assess equality of variances and to adjust t-values when variances were unequal. The results (see Table 1) show that scores in the RELD group were lower in absolute terms on all 16 variables and were significantly lower than the comparison PLA group on 5 variables: verbal comprehension, emotion understanding, theory of mind, response inhibition and working memory. Mean scores in the DCD group were lower in absolute terms on 9 of 13 variables and were significantly lower than the comparison PMC group on 5 variables: perceptual organization, verbal comprehension, receptive language, expressive language, and visual inspection time. In both clinical groups, scores were more uniformly low than among children with comparably poor language or motor skills.

Insert Table 1 about here

\section{Discussion}


Our aim was to assess whether children who have been diagnosed with specific developmental disorders have different ability profiles than children who are not identified with a disorder but have similar low scores on the ability defined by the disorder. That is, can these two types of children be distinguished based on the DSM criteria? We observed that children identified with a developmental disorder are more pervasive underachievers. Indeed, the conservative nature of our design and the relatively low power of our statistical tests due to small sample sizes suggest that our results may be an underestimate of the extent to which the underachievement of children with disorders is pervasive. The results imply that we need to reconsider how specific developmental disorders are defined and how research on them is conducted.

\section{Defining developmental disorders}

We suggested that how DSM defines specific developmental disorders describes what is expected of typical children whose performance in motor, language, or academic skills places them in the lower tail of a normal distribution. Based on the correlations between ability measures, we expected that a child with a standardized motor skills score of 70 would have IQ and standardized language scores of about 93 or 94. What we observed among typical children with a mean motor skills score of 67.2 was a mean IQ of 98.3 and a mean language score of 99.4. Similarly, we expected that a child with a standard language score of 70 would have an IQ of 82 and a standard motor skills score of 93.4. What we observed among typical children with a mean language score of 70.1 was a mean IQ of 86.3 and a mean motor skills score of 93.2. The discrepancies between IQ and other abilities that the DSM uses to define disordered underachievement are instead what is expected and what is observed among low achieving typical children. 
We suggested that a better index of disordered development, one that is consistent with the high rates of comorbidity among children diagnosed with any specific developmental disorder, may be a pattern of low achievement that is more pervasive than expected. In two groups of children with a specific developmental disorder and no diagnosed comorbid conditions, this is what we observed. In our DCD group, despite having marginally better fine motor coordination than typical children with poor motor skills, significant deficits in receptive and expressive language, perceptual organization and verbal comprehension, and visual inspection time were evident, a result that is consistent with evidence linking motor skills deficits with language impairments (Hill, 1998, 2001). Similarly, in our RELD group, despite the comparison group also having low scores on measures that are strongly related to language, the diagnosed children had significant deficits in executive functioning, in addition to deficits in social cognition and verbal comprehension, results that are consistent with evidence linking language impairments with working memory deficits (Archibald \& Gathercole, 2006; Botting, 2005).

The fact that children with specific developmental disorders are relatively pervasive underachievers tells us something about the character of the underlying impairment. As Karmiloff-Smith (2007, p. 84) has argued, developmental disorders cannot be explained "in terms of intact versus impaired modules; ... [rather], an early deficit in one part of the brain may have subtle effects on other parts of the developing brain, even when scores fall 'in the normal range'." The poor language skills of children in our DCD group might exemplify how a primary defect in an area like the cerebellum may affect other brain regions and cause problems other than with motor coordination. Diamond (2000) argued that projections from the neocerebellum and 
caudate nucleus, traditionally thought only to have specialised motor functions, play an important role in a wide range of cognitive tasks, including verb generation, verbal fluency, and nonmotor verbal working memory tasks that also involve the dorsolateral prefrontal cortex. The cerebellum is most involved when tasks - motor and nonmotor-are difficult, new, changing, timed, and require concentration (Diamond, 2000). Ullman and Pierpont (2005) suggested that the coincidence of language and motor deficits reflects impairment in frontal / basal ganglia circuits which underlie both motor and cognitive skills. Because of the connectiveness of the brain, and the plastic qualities of the developing brain, any defect may have extensive developmental effects.

Our results support the idea that relatively pervasive underachievement is a sign of developmental disorder, but they provide few clues as to what disorder might be affecting any given child. By presenting group means, our results obscure the extent to which individuals within each group differ from each other: the pattern that describes the group does not describe all children within the group. For example, the significantly lower language abilities that were observed in our DCD group result from the $50 \%$ of children in this group with standard language scores $<80$. If children in the DCD group with and without language problems are compared with each other, they differ significantly on measures of IQ, social cognition, verbal working memory and language. A prerequisite to understanding how best to describe and explain any developmental disorder may be that we study groups of children who are homogeneous across a broad range of characteristics, not just poor language or poor motor skills or poor attention. 


\section{Research on developmental disorders}

Just as our DCD group was heterogeneous, most samples studied in research on developmental disorders are heterogeneous and can be expected to consist of at least two distinct groups: normal low achievers and persons whose low achievement is due to neurodevelopmental disorder. In addition, even among those persons whose low achievement is due to disorder, more than one disorder may well have been sampled. Certain syndromes have a tendency to be comorbid with particular other syndromes. For example, children with ADHD are more likely than other children to have Oppositional Defiant Disorder whether or not they also have DCD, but children with DCD are more likely to have Asperger's Disorder if they have comorbid ADHD (Kadesjö \& Gillberg, 1999). By excluding children with known attentional problems, we reduced the chance that our DCD group would include persons with significant symptoms of Asperger's Disorder, but because we did not assess these symptoms in our sample, we cannot estimate to what extent such characteristics may be affecting our results.

The heterogeneity of groups in this and other studies may account for the lack of consistent results across investigations. In the context of DCD, Zoia et al. (2006) noted that "intra- and inter-individual variability within DCD is well documented" (p. 614). In his practitioner review, Wilson (2005) commented that as a result of inconsistent classification schemes and other controversies over the concept of DCD, “inter-study comparison and growth of knowledge of the disorder have been constrained" (p. 806). Wilson also noted the heterogeneity of children with DCD, suggesting that children "can show widely different profiles of performance" and “whether different sub-types of DCD exist remains an empirical question (p. 809). 
Both of these papers echo Visser (2003) who concluded his review of the DCD literature by saying: "there is more and more evidence that DCD is not a uniform disorder" (p. 488). What we suggest is that it is impossible to determine whether or not DCD is a uniform disorder when our ostensible DCD samples include both normal and disordered children and when the disordered children have inconsistent characteristics.

A second problem is that in researching developmental disorders, children with a disorder are commonly compared with mental age-matched younger typical children or children with some other disorder. This design assumes that among people with the same mental age, relationships between intelligence and other abilities will be the same unless they have been affected by a pathological process. This assumption is incorrect.

Children selected on the basis of underachievement in any area will always differ from 'average' children on a set of ability measures, not just on the selection measure. Table 1 shows that both groups of comparison children have low scores on variables other than language or motor coordination, and that scores vary across a large range. By contrast, in any sample of average children, all mean scores have the same expected value of 100 , that is, the expected value of discrepancy scores would be 0 . Because children selected on the basis of poor performance on one measure can be expected to perform from very poorly to average on a range of measures, comparing them with children whose performance across a set of tasks is average will pretty much inevitably result in significant between-group differences in performance. This principle can be illustrated with data from our PLA group. Children with a language disorder are typically matched on the basis of their non-verbal IQ. Our PLA 
group had a perceptual organization score of 89.2. Using one-sample t-tests to assess whether other ability scores differ significantly from this value, we would find that our PLA group had significantly lower scores on language measures. If these children, who represent the lower tail of an ability distribution, had been compared with average but younger typical children, the children in our comparison groups would have been found to be disordered.

A similar problem accompanies comparisons with children of comparable IQ but a different disorder. Depending on what ability is used to define the different disorder, different achievement profiles are to be expected. If we contrasted our PLA group with a clinical group of comparable intelligence (our DCD group), our PLA group would have clear deficits in language abilities. When children have been selected for low ability in some domain other than intelligence, using intelligence to match groups of children is likely to ensure that group differences on other ability measures will be observed.

\section{Limitations and Conclusions}

The major limitation of this study is that we cannot exclude the possibility that our results reflect systematic sampling error. In addition to the issue of the reliability of measurement, children in our clinical samples may have more uniformly low achievement than other low-scoring children because parents of children with multiple achievement deficits are more likely to seek professional help for their children than parents of children with a single deficit. Dyck, Hay et al. (2004) observed that underachievement in any ability domain was associated with increased parent-rated social and behavioural problems. If the social and behavioral problems of these children increase as the number of domains of underachievement increases, then 
the compounding of these social and behavioral problems would prompt clinical intervention.

We cannot exclude the possibility of sampling error, but think that this possibility is remote because our results are so closely consistent with what is predicted for normal low achieving children. It is time to recognize that current definitions of specific developmental disorders are so ill-conceived that the essential definition of disorder is a good description of a low achieving normal child and does not resemble the characteristics of children who are given a diagnosis of disorder. Rather than continue to distinguish specific disorders from pervasive ones, it is time to consider whether all children with a disorder are relatively pervasive underachievers and to focus on assessing the extent and breadth of underachievement, as well as any residual strengths, among these children. Such assessments would allow clearer distinctions to be drawn between the different patterns of underachievement that characterize children previously diagnosed with disorders like DCD or RELD, and how these relatively pervasive patterns of underachievement might differ from other pervasive disorders like autism. Pardoxically, ridding ourselves of current definitions of the so-called specific developmental disorders may be what allows us, finally, to identify specific, mutually discriminable patterns of developmental disorder. 


\section{What this paper adds}

\section{What is already known}

Previous research on the comorbidity of developmental disorders showed that children with a diagnosis of any one developmental disorder are likely also to satisfy diagnostic criteria for one or more other developmental disorders. This means that even though communication and motor skills disorders are defined as specific deficits in language or motor coordination relative to age and non-verbal or general intelligence, children with these disorders typically have multiple or pervasive ability deficits rather than specific ones. What is not clear is whether these children do indeed have multiple disorders or whether disordered development is characterised by relatively pervasive low achievement.

\section{What this study adds}

This study tested the hypothesis that a specific ability deficit is characteristic of normal low achievers and that more pervasive ability deficits result from disordered development. Children with a diagnosed communication or motor skills disorder had more pervasive ability deficits than normal low achievers, that is, children with equally poor language or motor skills who were selected from a representative sample (the bottom tail of the normal distribution) and who were not suspected of having a disorder. 


\section{References}

American Psychiatric Association (2000). Diagnostic and statistical manual of mental disorders $\left(4^{\text {th }}\right.$ ed., text revision). Washington, DC: American Psychiatric Association.

Anderson, M. (1988). Inspection time, information processing and the development of intelligence. British Journal of Developmental Psychology, 6, 43-57.

Archibald, L. M. D. \& Gathercole, S. E. (2006). Short-term and working memory in specific language impairment. International Journal of Language \& Communication Disorders, 41, 675-693.

Baron-Cohen, S., Leslie, A., \& Frith, U. (1985). Does the autistic child have a "theory of mind?" Cognition, 21, 37-46.

Botting, N. (2005). Non-verbal cognitive development and language impairment. Journal of Child Psychology \& Psychiatry, 36, 317-326.

Brookes, R. L., Nicolson, R. I. \& Fawcett, A. J. (2007). Prisms throw light on developmental disorders. Neuropsychologia, 45, 1921-1930.

Cummins, A., Piek, J., \& Dyck, M. (2005). Motor coordination, empathy and social behaviour in school aged children. Developmental Medicine \& Child Neurology, 47, 437-442.

Dewey, D., Kaplan, B. J., Crawford, S. G., \& Wilson, B. N. (2002). Developmental coordination disorder: Associated problems in attention, learning, and psychosocial adjustment. Human Movement Science, 21, 905-918.

Diamond, A. (2000). Close interrelation of motor development and cognitive development and of the cerebellum and prefrontal cortex. Child Development, 71, 44-56. 
Duncan, J., Emslie, H., \& Williams, P. (1996). Intelligence and the frontal lobes: The organization of goal-directed behavior. Cognitive Psychology, 30, 257-303.

Dyck, M., Farrugia, C., Shochet, I., \& Holmes-Brown, M. (2004). Emotion recognition / understanding ability in hearing or vision-impaired children: Do sounds, sights, or words make the difference? Journal of Child Psychology \& Psychiatry, 45, 789-800.

Dyck, M., Ferguson, K., \& Shochet, I. (2001). Do autism spectrum disorders differ from each other and from non-spectrum disorders on emotion recognition tests? European Child \& Adolescent Psychiatry, 10, 105-116.

Dyck, M., Hay, D., Anderson, M., Smith, L., Piek, J., \& Hallmayer, J. (2004). Is the discrepancy criterion for defining developmental disorders valid? Journal of Child Psychology \& Psychiatry, 45, 979-995.

Dyck, M., Piek, J., Hay, D., Smith, L., \& Hallmayer, J. (2006). Are abilities abnormally interdependent in children with autism? Journal of Clinical Child \& Adolescent Psychology, 35, 20-33.

Francis, D. J., Shaywitz, S. E., Stuebing, K. K., Shaywitz, B. A., Fletcher, J. M. (1996). Developmental lag versus deficit models of reading disability: A longitudinal, individual growth curves analysis. Journal of Educational Psychology, 88, 3-17

Gonzalez, J., \& Espinel, A. (1999). Is IQ-achievement discrepancy relevant in the definition of arithmetic learning disabilities? Learning Disability Quarterly, 22, 291-301.

Green, D., Baird, G., Barnett, A., Henderson, L., Huber, J. \& Henderson, S. (2002). Severity and nature of motor impairment in Asperger's syndrome: A 
comparison with specific developmental disorder of motor function. Journal of Child Psychology \& Psychiatry, 43, 655-668.

Happe, F. (1994). An advanced test of theory of mind: Understanding of story characters' thoughts and feelings by able autistic, mentally handicapped, and normal children and adults. Journal of Autism \& Developmental Disorders, $24,129-154$.

Harris, P., Johnson, C., Hutton, D., Andrews, G., \& Cooke, T. (1989). Young children's theory of mind and emotion. Cognition \& Emotion, 3, 379-400.

Henderson, S., \& Sugden, D. A. (1992). The movement assessment battery for children: Manual. Kent, England: The Psychological Corporation.

Hill, E. (1998). A dyspraxic deficit in specific language impairment and developmental coordination disorder? Evidence from hand and arm movements. Developmental Medicine \& Child Neurology, 40, 388-395.

Hill, E. (2001). Non-specific nature of specific language impairment: A review of the literature with regard to concomitant motor impairments. International Journal of Language \& Communication Disorders, 2, 149-171.

Kadesjö, B., \& Gillberg, C. (1999). Developmental coordination disorder in Swedish 7-year-olds. Journal of the American Academy of Child and Adolescent Psychiatry, 38, 820-828.

Kaplan, B., Wilson, B., Dewey, D., \& Crawford, S. (1998). DCD may not be a discrete disorder. Human Movement Science, 17, 471-490.

Karmiloff-Smith, A. (2007). Atypical epigenesis. Developmental Science, 10, 84-88. 
Karmiloff-Smith, A., Scerif, G. \& Ansari, D. (2003). Double dissociations in developmental disorders? Theoretically misconceived, empirically dubious. Cortex, 39, 161-163.

Larson, V. \& McKinley, N. (1995). Language disorders in older students. Eau Claire, WI: Thinking Publications.

Matsumoto, D., \& Ekman, P. (1995). Japanese And Caucasian Facial Expressions Of Emotion (JACFEE) And Neutral Faces (JACNeuF). San Francisco State University, San Francisco.

McCarron, L.T. (1997). McCarron Assessment of NeuroMuscular Development: Fine and Gross Motor Abilities (rev. ed.). Dallas, TX: Common Market Press

Perner, J., Frith, U., Leslie, A., \& Leekam, S. (1989). Exploration of the autistic child's theory of mind: Knowledge belief and communication. Child Development,60, 689-700.

Perner, J. \& Wimmer, H. (1985). “John thinks that Mary thinks that...” Attribution of second-order beliefs by 5-to 10-year-old children. Journal of Experimental Child Psychology, 39, 437-471.

Piek, J., Dyck, M., Francis, M., \& Conwell, A. (2007). Working memory, processing speed, and set-shifting in children with developmental coordination disorder and attention deficit hyperactivity disorder. Developmental Medicine \& Child Neurology, 49, 678-683.

Piek, J., Pitcher, T., \& Hay, D. (1999). Motor coordination and kinaesthesis in boys with attention deficit-hyperactivity disorder. Developmental Medicine \& Child Neurology, 41, 159-165. 
Rabbit, P. (1997). Methodology of frontal and executive function. East Sussex, UK: Psychology Press.

Ramus, F., Pidgeon, E., \& Frith, U. (2003). The relationship between motor control and phonology in dyslexic children. Journal of Child Psychology \& Psychiatry, 44, 712-722.

Semel, E., Wiig, E., \& Secord, W. (1995). Clinical evaluation of language fundamentals ( $3^{\text {rd }}$ ed.): Technical manual. San Antonio, TX: The Psychological Corporation.

Shue, K., \& Douglas, V. (1992). Attention deficit hyperactivity disorder and the frontal lobe syndrome. Brain \& Cognition, 20, 104-124.

Stanovich, K., \& Stanovich, P. (1997). Further thoughts on aptitude/achievement discrepancy. Educational Psychology in Practice, 13, 3-8.

Sternberg, R., \& Grigorenko, E. (2002). Difference scores in the identification of children with learning disabilities: It's time to use a different method. Journal of School Psychology, 40, 65-83.

Ullman, M. T. \& Pierpont, E. I. (2005). Specific language impairment is not specific to language: The procedural deficit hypothesis. Cortex, 41, 399-433.

Vellutino, F., Scanlon, D., \& Lyon, G. (2000). Differentiating between difficult-toremediate and readily remediated poor readers: More evidence against the IQachievement discrepancy definition of reading disability. Journal of Learning Disabilities, 33, 223-238.

Vellutino, F. R., Fletcher, J. M., Snowling, M. J. \& Scanlon, D. M. (2004). Specific reading disability (dyslexia): what have we learned in the past four decades? Journal of Child Psychology and Psychiatry, 45, 2-40. 
Visser, J. (2003). Developmental Coordination Disorder: A review of research on subtypes and comorbidities. Human Movement Science, 22, 479-493.

Wechsler, D. (1992). Wechsler intelligence scale for children - Third edition: Manual. San Antonio, TX: The Psychological Corporation.

Wilson, P. H. (2005). Practioner review: Approaches to assessment and treatment of children with DCD: An evaluative review. Journal of Child Psychology \& Psychiatry, 46, 806-823.

Wimmer, H. \& Perner, J. (1983). Beliefs about beliefs: Representation and constraining function of wrong beliefs in young children's understanding of deception. Cognition, 13, 103-127.

Wisdom, S., Dyck, M., Piek, J., Hay, D., \& Hallmayer, J. (2007). Can autism, language and coordination disorders be differentiated based on characteristic ability profiles? European Child \& Adolescent Psychiatry, 16, 178-186.

World Health Organisation (1992). The ICD-10 classification of mental and behavioural disorders. Geneva: World Health Organisation.

Zoia, S., Barnett, A., Wilson, P., \& Hill, E. (2006). Developmental Coordination Disorder: Current issues. Child: Care, Health, \& Development, 32, 613-618. 
Normal \& Disordered Low Achievement

Author Notes

This research was supported by grants from the Australian National Health and Medical Research Council and the Research Centre for Applied Psychology, Curtin University of Technology. We wish to thank the principals and staff of participating schools and clinics for their cooperation, and especially to thank the participating children and parents who made this study possible. 
Normal \& Disordered Low Achievement

Table 1

Ability differences between children with RELD and typical children with poor language ability, and between children with DCD and typical children with poor motor skills

\begin{tabular}{|c|c|c|c|c|}
\hline & RELD & PLA & DCD & PMC \\
\hline \multirow[t]{2}{*}{ Receptive Language } & $66.5(18.2)$ & $71.1(10.2)$ & $81.8(21.9)^{b}$ & $95.9(17.7)^{b}$ \\
\hline & $\mathrm{n}=20$ & $\mathrm{n}=22$ & $\mathrm{n}=20$ & $\mathrm{n}=27$ \\
\hline \multirow[t]{2}{*}{ Expressive Language } & $73.0(14.8)$ & $74.3(13.1)$ & $90.1(21.6)^{b}$ & $102.6(10.8)^{b}$ \\
\hline & $\mathrm{n}=19$ & $\mathrm{n}=22$ & $\mathrm{n}=20$ & $\mathrm{n}=28$ \\
\hline \multirow[t]{2}{*}{ Fine Motor Skills } & $95.8(15.5)$ & $96.4(13.3)$ & $78.9(19.8)$ & $73.4(14.5)$ \\
\hline & $\mathrm{n}=21$ & $\mathrm{n}=22$ & $\mathrm{n}=20$ & $\mathrm{n}=29$ \\
\hline \multirow[t]{2}{*}{ Gross Motor Skills } & $86.1(22.9)$ & $91.4(15.5)$ & $69.0(25.8)$ & $68.4(8.7)$ \\
\hline & $\mathrm{n}=21$ & $\mathrm{n}=22$ & $\mathrm{n}=20$ & $\mathrm{n}=28$ \\
\hline \multirow[t]{2}{*}{ Perceptual Organization } & $83.0(15.2)$ & $89.2(21.0)$ & $87.1(17.2)^{b}$ & $96.5(16.9)^{b}$ \\
\hline & $\mathrm{n}=21$ & $\mathrm{n}=22$ & $\mathrm{n}=20$ & $\mathrm{n}=28$ \\
\hline \multirow[t]{2}{*}{ Verbal Comprehension } & $78.4(13.9)^{a}$ & $86.8(15.1)^{a}$ & $86.8(18.5)^{b}$ & $100.4(16.4)^{b}$ \\
\hline & $\mathrm{n}=21$ & $\mathrm{n}=22$ & $\mathrm{n}=20$ & $\mathrm{n}=28$ \\
\hline \multirow[t]{2}{*}{ Emotion Recognition } & $84.9(12.7)$ & $88.8(16.9)$ & $85.8(14.6)$ & $93.4(16.1)$ \\
\hline & $\mathrm{n}=21$ & $\mathrm{n}=22$ & $\mathrm{n}=20$ & $\mathrm{n}=28$ \\
\hline \multirow[t]{2}{*}{ Emotion Understanding } & $76.7(10.8)^{a}$ & $87.1(14.2)^{a}$ & $94.3(17.9)$ & $95.3(15.2)$ \\
\hline & $\mathrm{n}=21$ & $\mathrm{n}=22$ & $\mathrm{n}=20$ & $\mathrm{n}=28$ \\
\hline \multirow[t]{2}{*}{ Theory of Mind } & $73.0(23.0)^{a}$ & $84.6(18.0)^{a}$ & $91.6(22.0)$ & $94.3(18.9)$ \\
\hline & $\mathrm{n}=21$ & $\mathrm{n}=22$ & $\mathrm{n}=20$ & $\mathrm{n}=28$ \\
\hline
\end{tabular}




\begin{tabular}{|c|c|c|c|c|}
\hline Response Inhibition & $75.1(38.0)^{\mathrm{a}}$ & $108.1(11.2)^{\mathrm{a}}$ & $108.4(18.8)$ & $103.3(9.8)$ \\
\hline & $\mathrm{n}=14$ & $\mathrm{n}=15$ & $\mathrm{n}=18$ & $\mathrm{n}=21$ \\
\hline \multirow[t]{2}{*}{ Working Memory } & $75.1(25.7)^{\mathrm{a}}$ & $93.4(17.2)^{\mathrm{a}}$ & $81.0(17.0)$ & $89.8(16.5)$ \\
\hline & $\mathrm{n}=13$ & $\mathrm{n}=15$ & $\mathrm{n}=15$ & $\mathrm{n}=19$ \\
\hline \multirow[t]{2}{*}{ Visual Inspection Time } & $83.4(35.2)$ & $99.1(14.4)$ & $83.1(32.8)^{b}$ & $99.6(18.8)^{b}$ \\
\hline & $\mathrm{n}=13$ & $\mathrm{n}=13$ & $\mathrm{n}=16$ & $\mathrm{n}=20$ \\
\hline
\end{tabular}

groups differ significantly at .05 level, one-tailed

Note: Composites may have lower or higher standard scores than their constituent variables as a result of the standardization process. 